\title{
Single Minute Exchange of Die and Innovations are Join Vessels
}

\author{
Frantisek HASEK, Hana MOHELSKA \\ University of Hradec Kralove, Hradec Kralove, Czech Republic \\ \{frantisek.hasek, hana.mohelska\}@uhk.cz
}

\begin{abstract}
Competitive capability of companies is increased by many methods, companies are still looking for other ways to increase their efficiency. One of these ways is Lean Manufacturing, which includes a very effective method called Single Minute Exchange of Die (SMED), which reduces the time needed for the changeover. The need for this method still grows with bigger and bigger customization of products. As a result of customization, the number of changeovers grows too. The setup activities which do not interfere with the equipment, and which can be carried out without interrupting production, are determined as being external activities. Many internal activities can be transformed to external or make them more efficient by innovations. The article describes not only the benefits of innovation in a selected manufacturing company but also explains the benefits of implementing the Single Minute Exchange of Die method in general. It is mainly the overall increase of the company's efficiency, better use of the workforce and the technological development of the company thanks to the incentives for innovation resulting from the output of the SMED method. The aim of the article is to collect the current knowledge about the method, case studies and a summary of the general benefits of the method application.
\end{abstract}

Keywords: Single Minute Exchange of Die, Lean, Lean Manufacturing. Lean Innovation.

\section{$1 \quad$ Introduction}

Lean manufacturing is a philosophy based on the resource-efficient economy. It shows how important it is to eliminate wasting which arises during the production process. The most significant resource of wasting is overproduction, retooling, failures, scrap, inventory, movement, or transport. It is possible to reduce these kinds of wasting by 5S, Total Production Maintenance, Value Stream Mapping, Just in Time and many others [8]. It also helps to meet the client's requirements in required quality and desired delivery time [5].

Many companies designate, as the best possible choice, the small-scale production where many types of customized products are required. The most significant difference and also the problem between small and large-scale production is the high increase in the number of changeovers [7]. Production efficiency depends on many different 
factors, changeover is one of the most time-consuming, non-value-added activity in many industries. Particularly in the case of frequent changeover in small-scale production, this type of wasting has a considerable impact on the overall efficiency of the company. Some reduction is necessary in this case [2].

Single Minute Exchange of Die (SMED) was developed in the middle of the 20th century by Shingeo Shingo, the Toyota employee. With this method he has achieved excellent results on car body molding procedure thanks to the organization of processes and simple innovations[4].

\section{Theoretical Background}

Setting up, changing tools, rebuilding machines, etc. are often the last areas to look for wasting and inefficiency. Each rebuilding is a waste because it is not the added value of the final product and the time consumed for the changeover could be used for production [8]. These activities are often wasting time especially during the time that production workers are waiting for finishing of the changeover. Production is not possible during this time. The SMED system also improves safety and improves workplace ergonomics [4], its main essence is the division of adjustment operations into two basic categories:

- Internal activities (tool adjustment, exchange of rotate parts, etc.) that can only be performed when the machine is stopped.

- External activities (transport from the warehouse, preparation of all necessary parts and tools, presetting of various parts), which can be performed even when the machine is running [6].

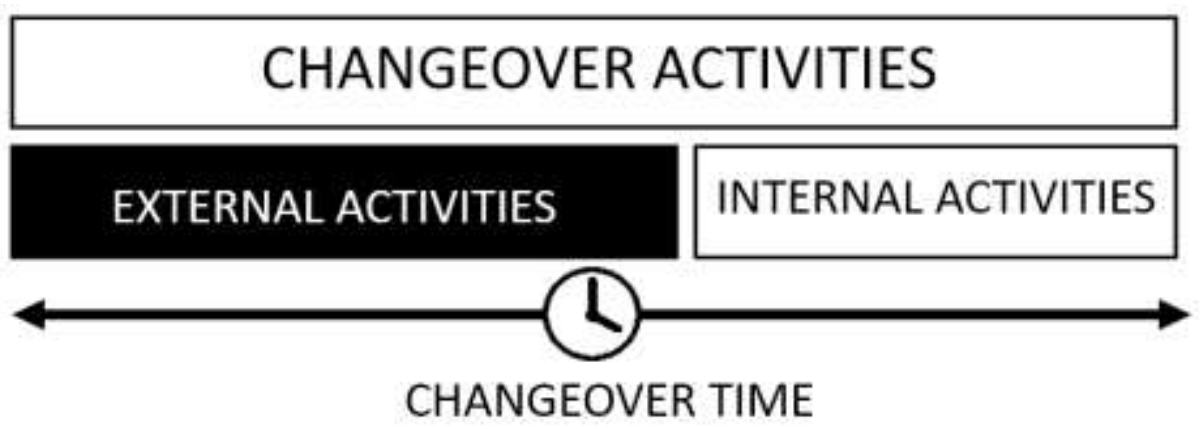

Fig. 1. - Internal and external operations - SMED.

The key aspect of SMED methodology is the distinction between changeover activities when the machine is not running (internal activities) and activities where the machine can be started (external activities). The SMED reduces the time when the machine is stopped. The SMED method is consists of one preparatory [2] and three main steps [3]: 
- Step 0 provides a complete overview of the changeover process, such as a checklist, observation, or changeover manual [2].

- Step 1 focuses on dividing activities into two of the above groups by asking: "Do I have to stop the machine to do this?".

- Step 2 transforms an internal activity into external. It can drastically reduce the nonproductive time. These savings can be achieved by adjusting the device, removing long settings when the machine is stopped or standardizing the size of tools.

- Step 3 increases and simplifies all aspects of the internal and external operations undergoing during changeover by using the specific principles and innovations [3].

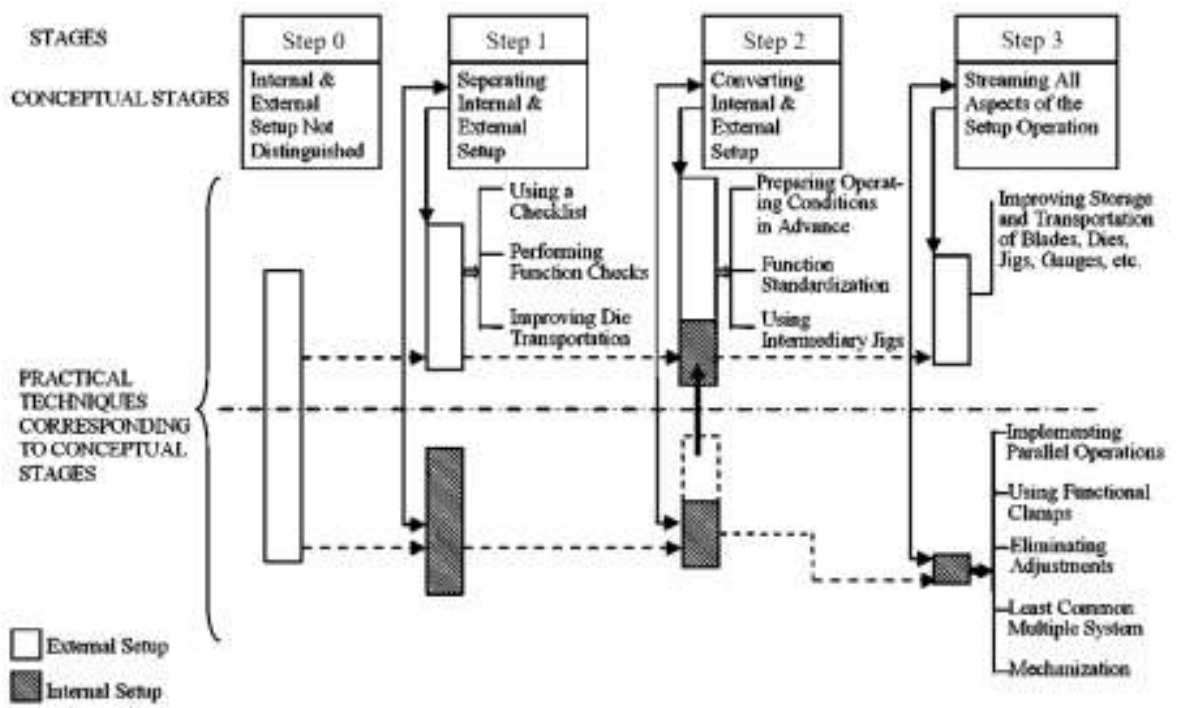

Fig. 2. SMED - Steps [3].

SMED focuses exclusively on machine changeover operations, but in many cases changeovers are affected by the previous type of production. This justifies the development of new methods that help professionals to detect inadequate optimization in other business processes which can reveal the underlying causes of problems for example with previous operations or with the previous product type [2].

Changeover time is the time elapsed between making the last good piece of the first dose and the first good piece of the second dose. SMED method is often compared with pit stops in Formula 1 racing, where tank filling, tire replacement, repairs, and other activities have to take place in the shortest possible time [1]. Activities should be analyzed from a different point of view in order to objectively describe all steps and activities, including at first sight obvious shortcomings [7]. 


\section{Case Study}

This method has been applied in a medical company which manufactures plasters, tampons, instruments, and Medisets. Paret's diagram found that the most downtime in the Medisets workplace was due to the changeovers of machines to various types of products, which are around 1500. When the machine is in the changeover, the machine is stopped, and the workers are waiting for the adjustment to be done by the adjuster. Due to the significant number of product types, it is not possible to analyze and create a proposal for improvement for all types of products, so the changeovers are divided into several types, and the SMED method is used to optimize them.

All lines work on a similar principle, their basis of which are forms of different dimensions, including several types of forms, through which the foil is formed. The foil is used in several thicknesses, like paper that is welded together with the foil after filling of the components.

One shift has up to fifty changeovers. For this reason, it is highly desirable to shorten the changeovers to the shortest possible time, because the time is profitable only when the line can run.

\subsection{Step 0}

The first phase of SMED is to find available information about the changeover, for example, checklist or standards. In some cases, it is possible to analyze and optimize the standards. Employees do not have to work according to the standards, but they can often do it at their own discretion. The best option is therefore direct observation or video recording of the process. The record can be later conveniently analyzed into detail or used for educational purposes. Another advantage is to save time by creating a Spaghetti diagram directly from the record. Selected types of rebuilds were filmed and processed. As an illustration of this article, a Tiromat changeover was selected to replace paper, print and shaping vats. The following table shows setter's activities. The diagram on the right of the table shows the sequence of activities and their time requirements. The dark grey color depicts the waste, the light grey activities that should be external, black are internal activities, and the white color indicates innovations. The column labeled Time represents the duration of each activity, the sub-column then shows the cumulative activity time. The total length of this changeover is greatly prolonged by many trays between the molding of the tub and the final cut. The total time from the line stop to the first correct piece of the product is 10 minutes and 21 seconds. 
Table 1. SMED - Step 0

\begin{tabular}{|c|c|c|c|c|c|c|c|c|c|c|c|c|c|}
\hline \multirow{2}{*}{ Working step } & \multirow{2}{*}{$\stackrel{\Xi}{\Xi}$} & \multirow{2}{*}{ 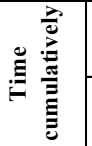 } & \multicolumn{11}{|c|}{ Timetable: 0 - 11 Minutes } \\
\hline & & & 1 & 2 & 3 & 4 & 5 & 6 & 7 & 8 & 9 & 10 & 11 \\
\hline Last good piece & $0: 00: 00$ & 0:00:00 & & & & & & & & & & & \\
\hline Walking to the forms & $0: 00: 08$ & 0:00:08 & & & & & & & & & & & \\
\hline Acces to the form & 0:00:12 & 0:00:20 & & & & & & & & & & & \\
\hline Walking for forms & 0:01:13: & 0:01:33 & & & & & & & & & & & \\
\hline Replacement of the form & $0: 00: 25$ & 0:01:58 & & & & & & & & & & & \\
\hline Covering the forms & 0:00:07 & 0:02:05 & & & & & & & & & & & \\
\hline Walking & 0:00:07 & 0:02:12 & & & & & & & & & & & \\
\hline Paper change & 0:00:40 & $0: 02: 52$ & & & & & & & & & & & \\
\hline Preparation of the label & 0:00:41 & 0:03:33 & & & & & & & & & & & \\
\hline Label printing & $0: 00: 20$ & 0:03:53 & & & & & & & & & & & \\
\hline Preparation of paper print & 0:00:45 & $0: 04: 38$ & & & & & & & & & & & \\
\hline Printing of paper & $0: 00: 12$ & $0: 04: 50$ & & & & & & & & & & & \\
\hline Starting the machine & $0: 00: 21$ & $0: 05: 11$ & & & & & & & & & & & \\
\hline Waiting for new paper to be loade & $0: 01: 31$ & 0:06:42 & & & & & & & & & & & \\
\hline Inserting the material to the forms & $0: 00: 42$ & 0:07:24 & & & & & & & & & & & \\
\hline First good piece & $0: 02: 57$ & $0: 10: 21$ & & & & & & & & & & & \\
\hline
\end{tabular}

\section{2 $\quad$ Step 1}

The activities that can be performed while the line is running, before the changeover is started, are often performed as internal operations, and the time needed to carry out the changeover is disproportionately increasing. In the first step of the SMED, these activities will be sorted out without the line stops. During analyzing it is critical to talk with all of the setters. Some of them can improve the changeover process themselves. As mentioned in the null phase, the preparation of label and paper printing is an activity that can be done without the machine stopping and even walking is a waste of time that needs to be eliminated. That is why bringing forms is allocated as an external operation. The setter must prepare the necessary forms directly on the line before the start of the changeover. Another item among the external list activities is the transition forms from the line's output to the opposite side. 
Table 2. SMED - Step 1.

\begin{tabular}{|c|c|c|c|c|c|c|c|c|c|c|c|c|}
\hline \multirow{3}{*}{ Working step } & \multirow{3}{*}{$\stackrel{\Xi}{\Xi}$} & \multirow{3}{*}{ 咅 } & \multicolumn{10}{|c|}{ Timetable: -3 - 8 Minutes } \\
\hline & & & \begin{tabular}{|l|l|}
-3 & -2
\end{tabular} & -1 & 1 & 2 & 3 & 4 & 5 & 6 & 7 & 8 \\
\hline & & & \multicolumn{2}{|c|}{ External activities } & \multicolumn{8}{|c|}{ Internal activities } \\
\hline Walking to the forms & $-0: 00: 08$ & $-0: 02: 47$ & & & & & & & & & & \\
\hline Walking for forms & $-0: 01: 13$ & $-0: 02: 39$ & & & & & & & & & & \\
\hline Preparation of the label & $-0: 00: 41$ & $-0: 01: 26$ & & & & & & & & & & \\
\hline Preparation of paper print & $-0: 00: 45$ & $-0: 00: 45$ & & & & & & & & & & \\
\hline Last good piece & 0:00:00 & 0:00:00 & & & & & & & & & & \\
\hline Acces to the form & 0:00:12 & 0:00:12 & & & & & & & & & & \\
\hline Replacement of the form & 0:00:25 & $0: 00: 37$ & & & & & & & & & & \\
\hline Covering the forms & 0:00:07 & 0:00:44 & & & & & & & & & & \\
\hline Walking & 0:00:07 & 0:00:51 & & & & & & & & & & \\
\hline Paper change & 0:00:40 & 0:01:31 & & & & & & & & & & \\
\hline Label printing & 0:00:20 & 0:01:51 & & & & & & & & & & \\
\hline Printing of paper & 0:00:12 & 0:02:03 & & & & & & & & & & \\
\hline Starting the machine & 0:00:21 & 0:02:24 & & & & & & & & & & \\
\hline Waiting for new paper to be loade & 0:01:31 & 0:03:55 & & & & & & & & & & \\
\hline Inserting the material to the forms & 0:00:42 & 0:04:37 & & & & & & & & & & \\
\hline First good piece & 0:02:57 & 0:07:34 & & & & & & & & & & \\
\hline
\end{tabular}

If the operator stops the product line at the output with the last correct piece, the setter can immediately begin replacing the forms. Getting ready to print labels and paper is another significant time-saving. The setter should take a laptop with him for the changeover, where he can prepare labels with the necessary information before he starts. According to the information obtained from the setters, it is possible to send the necessary data to the printer directly even if it is running, then just confirm the new printing. On the other hand, in the case of a label printer, it is not possible to send data while the printer is running. So it is necessary to prepare the data so that it can be printed simply by using the keyboard shortcut $\mathrm{Ctrl}+\mathrm{P}$. Delegating these activities will take 2 minutes and 47 seconds to save, and the total time is reduced to 7 minutes and 34 seconds. The value in the first row of the table, in the cumulative sum column, shows the time needed to prepare before the changeover. This time could be displayed on the monitor above the appropriate line. The setter would have more time to organize his work.

\subsection{Step 2}

In the second step, internal operations are converted to external. There is space for software and hardware innovations because small innovations can change the process. It is possible here to make software innovation with the printer. Now it is not possible to send new print data to the printer without stopping printing. This line has many choices to increase efficiency by innovations - for example, the innovative way how to change forms, new way how to guide cover paper into the line or change foil guidance. These innovations have a lot of potentials. 


\subsection{Step 3}

The third step of the SMED method reduces and speeds up changeovers and concerns both internal and external activities. The most significant change is to eliminate the waiting time for the scrolling of new paper. The paper is rolled out from the roller through the roller system in which two meters of paper are stretched. When starting up, the machine must form several drums corresponding to two meters of foil. By innovation during stretching and attaching old and new paper to the last accessible drum before the printer is fed by paper the waiting time is shortened for more than 1 and a half minutes. This work step was set aside among external operations, resulting in the ten-second paper change needed to stretch the paper through the guide roller system. The total changeover time is reduced by more than $41 \%$ from 10 minutes and 21 seconds to almost 6 minutes.

Table 3. SMED - Step 3.

\begin{tabular}{|c|c|c|c|c|c|c|c|c|c|c|c|c|c|}
\hline \multirow{3}{*}{ Working step } & \multirow{3}{*}{$\stackrel{\mathscr{\Xi}}{:}$} & \multirow{3}{*}{ 竞 } & \multicolumn{11}{|c|}{ Timeline: -5 - 6 Minutes } \\
\hline & & & -5 & -4 & -3 & -2 & -1 & 1 & $2 \mid$ & 3 & 4 & 5 & 6 \\
\hline & & & \multicolumn{5}{|c|}{ External activites } & \multicolumn{6}{|c|}{ Internal activities } \\
\hline Waiting for new paper to be loaded & $-0: 01: 31$ & 0:00:00 & & & & & & & & & & & \\
\hline Walking to the forms & $-0: 00: 08$ & $-0: 02: 47$ & & & & & & & & & & & \\
\hline Walking for forms & $-0: 01: 13$ & $-0: 02: 39$ & & & & & & & & & & & \\
\hline Preparation of the label & $-0: 00: 41$ & $-0: 01: 26$ & & & & & & & & & & & \\
\hline Preparation of paper print & $-0: 00: 45$ & $-0: 00: 45$ & & & & & & & & & & & \\
\hline Last good piece & $0: 00: 00$ & 0:00:00 & & & & & & & & & & & \\
\hline Acces to the form & $0: 00: 04$ & 0:00:04 & & & & & & & & & & & \\
\hline Replacement of the form & 0:00:25 & $0: 00: 29$ & & & & & & & & & & & \\
\hline Covering the forms & $0: 00: 03$ & $0: 00: 32$ & & & & & & & & & & & \\
\hline Walking & 0:00:07 & $0: 00: 39$ & & & & & & & & & & & \\
\hline Paper change & $0: 00: 50$ & 0:01:29 & & & & & & & & & & & \\
\hline Label printing & $0: 00: 20$ & $0: 01: 49$ & & & & & & & & & & & \\
\hline Printing of paper & $0: 00: 12$ & 0:02:01 & & & & & & & & & & & \\
\hline Starting the machine & $0: 00: 21$ & $0: 02: 22$ & & & & & & & & & & & \\
\hline Inserting the material to the forms & $0: 00: 42$ & 0:03:04 & & & & & & & & & & & \\
\hline First good piece & $0: 02: 57$ & 0:06:01 & & & & & & & & & & & \\
\hline
\end{tabular}

\section{$4 \quad$ Results and Discussion}

This article was developed with the aim of reducing changeover by application of the SMED methodology and description of innovations resulting from the method. Pareto's analysis revealed the greatest downtime in the workplace called Mediset's. The largest of these is the changeover of machines to another type of production. For this type of downtime, the SMED method was applied, which aims to set aside the external actions performed during the changeover without stopping the line which increases the productivity. SMED method saved on the analyzed working environment more than $40 \%$ of the time required for the changeover. Optimization has been done by innovation of paper guidance. Optimization of all types of rebuilding will result in very 
significant savings as up to 50 changeovers are made per day which takes up to several hours a day at this workplace. The output of this method is incentives for improvement and innovation. Further optimization can be done through more complex or simpler innovations in the production line which can achieve greater efficiency.

\section{References}

1. Ahmad, R., Soberi, M.S.F.: Changeover process improvement based on modified SMED method and other process improvement tools application: an improvement project of 5-axis $\mathrm{CNC}$ machine operation in advanced composite manufacturing industry. The International Journal of Advanced Manufacturing Technology. 94, 14, 433-450 (2018), DOI:10.1007/s00170-017-0827-7.

2. Braglia, M. et al.: SMED enhanced with 5-Whys Analysis to improve setupreduction programs: the SWAN approach. The International Journal of Advanced Manufacturing Technology. 90, 5-8, 1845-1855 (2017), DOI: 10.1007/s00170016-9477-4.

3. Cakmakci, M.: Process improvement: performance analysis of the setup time reduction-SMED in the automobile industry. The International Journal of Advanced Manufacturing Technology. 41, 1-2, 168-179 (2009), DOI: 10.1007/s00170-008$1434-4$.

4. Chiarini, A.: Lean Organization: from the Tools of the Toyota Production System to Lean Office. Springer Milan, Milano (2013), DOI: 10.1007/978-88-470-2510-3.

5. Martins, M. et al.: A Practical Study of the Application of SMED to Electron-beam Machining in Automotive Industry. Procedia Manufacturing. 17, 647-654 (2018), DOI: 10.1016/j.promfg.2018.10.113.

6. Mašín, I., Vytlačil, M.: Nové cesty k vyšší produktivitě: metody průmyslového inženýrství. Institut průmyslového inženýrství, Liberec (2000), ISBN: 978-80902235-6-1.

7. Shingō, S.: A revolution in manufacturing: the SMED system. Productivity Press, Stamford, Conn (1985) ISBN: 978-0-915299-03-4.

8. Comparative Analysis of the Implementation of the SMED Method on Selected Production Stands. Tehnicki vjesnik - Technical Gazette. 25, Supplement 2, (2018) DOI: $10.17559 / \mathrm{TV}-20160411095705$. 